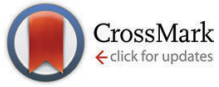

Cite this: Phys. Chem. Chem. Phys., 2016, 18, 13130

DOI: $10.1039 / c 6 c p 90107 g$

www.rsc.org/pccp

\section{Correction: Water-mediated long-range interactions between the internal vibrations of remote proteins}

\author{
Anna Kuffel and Jan Zielkiewicz*
}

Correction for 'Water-mediated long-range interactions between the internal vibrations of remote proteins' by Anna Kuffel et al., Phys. Chem. Chem. Phys., 2015, 17, 6728-6733.

The authors would like to correct an error in the published Acknowledgements.

The sentence:

"This work was also supported by the Republic of Poland within the research grant No. 2013/09/D/NZ1/01087."

should be replaced with the following one:

"This work was supported by the Polish National Science Centre within the research grant No. DEC-2013/09/D/NZ1/01087."

The authors apologize for omitting the name of the National Science Centre.

The Royal Society of Chemistry apologises for these errors and any consequent inconvenience to authors and readers. 